\title{
CLINICAL PSYCHOLOGY OF CORPOREALITY: PRINCIPLES OF CULTURAL-HISTORICAL SUBJECT ANALYSIS
}

\author{
Valentina V. Nikolaeva, \\ Galina A. Arina \\ Lomonosov Moscow State University \\ Moscow
}

The psychology of corporeality is a new and intensively elaborated branch of science. The theoretical foundations of its subject differ significantly from those of medical psychosomatics. In a given article some new concepts of this approaching discipline are introduced and the role of symbolic mediation in genesis of different psychosomatic diseases is discussed.

Keywords: psychology of corporeality, psychosomatics, psychosomatic development, psychosomatic dysontogenesis, symbolic mediation, higher psychological processes, activity, internal picture of illness, symptom appearance, syndromic analysis.

There are two main tendencies in the development of Russian clinical psychology in the 20th Century. One of them is the gradual and successive separation from medicine that includes the apportionment and the specification of the psychological research subject and its practical activities. The other one is the differentiation of the separated fields inside clinical psychology by means of expansion of problems and description of new clinical phenomena including those that have never been studied (Polyakov, 1995).

Consequently, a new field of clinical psychology is being developed very intensely. This new field is called the psychology of corporeality, and it originated from the previous development of the psychosomatic approach in medicine. But the subject and the direction of psychological studies in psychology of corporeality are not the same as those traditional ones in psychosomatic medicine (Engel, and Schmale, 1967; Sifneos, 1973).

The development of psychology of corporeality in the wealth of medicine has determined the circle of clinical phenomena, in which gen- 
esis and dynamics psychological factors play very important role. Inclusion of the mind-body problem in the mainstream of general medicine means that the term "psychosomatics" has now become a term wholly referring to the area of pathopsychology. The simple use of the concept is now construed to be an unequivocal indication of the presence of pathopsychological phenomena in human body secondary to effects of pathogenic psychological factors. Such an approach, however, places a vast range of psychosomatic phenomena under normal conditions beyond the pale of scientific analysis (Tkhostov, 2002). The existence of such phenomena in normal human beings can hardly be doubted: suffice it to mention the conditions quite familiar to psychologists, when a person is able to mobilize considerable physical and mental resources in a situation requiring resolution of a difficult and responsible task, or that of affective disorganization with marked physical components.

There are implicit presentations in science that strictly human in human is limited to mind, and body is just a biological condition for mind development. We consider that such views prevent the inclusion of the mind-body problem in psychology. As the result, only mind and the right hand are present in psychological studies. The rest of the human corporeality is represented in studies of natural sciences (physiology, anatomy, biology, etc.) (Tishenko, 1989).

Thus, the object field of psychosomatics is paradoxical and even defective. Nowadays, despite the wide range of interdisciplinary phenomenology only specific narrow understanding of this phenomenology is spread (medical approach). So the first (and the principal) tasks of psychologists examining the mind-body problem are to define the subject of studies in this area, to specify the discrete scientific psychological problems involved, and to indicate ways to approach them.

Vygotsky's concepts could serve as a theoretical and methodological basis for a fundamentally new approach to the mind-body problem. Vygotsky thought that human corporeal processes required a new understanding. Hence, we read in fragments from his notebooks: "My point of view entails: unity of psychophysiological processes and primacy of the psychological aspect; study of psychological processes, giving overriding emphasis to their psychophysiological aspects. Most important: the possibility, introduced by consciousness, of a new movement, of a new change in psychophysiological processes, of new connections and a new type of development of functions - in particular, historical develop- ment, with changes in interfunctional relations - an impossible case at the level of organic development: psychological systems. The possibility of social conscious experience and hence the primacy of conscious structures built from without, through communication: what is impossible for one possible for two... The idea of psychological physiology" (Vygotsky, 1982, p. 66).

The cultural-historical concept of mind development allows qualitative change of the general idea about human body development (normal and abnormal). Body development has to deal with general mental development and therefore it is not limited by progress and changing of physiological system. According to this approach, human body has been changing by culture. During human ontogeny body becomes the first universal symbol and the instrument of human development. Thus human physiological systems acquire a new quality, originating, so to speak, from above, as a consequence of cultural-historical genesis of consciousness. It can be applied to the whole of human somatic sphere, which also acquires a new quality in the course of human cultural evolution. Body has the ability to reap the fruits of all psychological development. This idea is not new; it has been widely discussed in the traditional psychoanalysis. From its point of view the grafting of psychological abilities could lead to the threat of appearance of a psychosomatic symptom, and science here is an interference of mental into corporal, which also could be pathological. Thanks to normal psychological ontogeny body acquires good reforming mechanisms and phenomena.

In psychoanalysis the concepts of "symptom" and "phenomenon" either have the same interpretation and meaning or "symptom" is understood as regression to a position, when the mental and the corporal were not differentiated (the concept of resomatics). According to the cultural-historical concept, there is an ability to distinguish psychosomatic phenomena and symptoms in normal and abnormal development from the very beginning. A psychosomatic phenomenon is not identical with a psychosomatic symptom; it is a consequence of socialization of human corporeality, i.e., of psychosomatic development. The nature of psychosomatic phenomena derives from new psychological structures, and is transformed in accordance with the logic of mental development. The path of socialization of corporeal phenomena lies through the generation and assimilation of corporeal signs, imparting meaning to them, the expansion of bodily actions network. 
The acquiring of the sign system transforms structure of corporeal experience. The formed psychosomatic phenomenon includes body activities and their cognitive and meaning regulating systems, therefore the psychosomatic phenomenon acquires the traits of the higher psychological processes: their social development, mediated nature, the ability to be controlled at will. From this point of view psychosomatic pathology can be a consequence of a breakdown of the corporal developmental socialization.

We consider that the psychology of corporeality has its own phenomenological aspect which is determined by culture, and its development has to deal with the mental development. A new line of development (the psychosomatic development) can be marked out along the mental and the corporal development.

The child's psychosomatic development can be understood as a formation of psychological regulation mechanisms of corporal systems obeying the laws of nature. The subjects of that process are cultural forms of realization of natural needs (to eat, to drink and etc.), corporal functions (breathing, pain reaction), and new psychosomatic phenomena (body image, pain image). This process deals with cognitive elements, meanings, emotional reactions, corporal activity.

The first bearer of a psychosomatic phenomenon is the motherchild dyad, thanks to which the symbolic level exists from the very outset along with the natural level of a psychosomatic phenomenon. In jointly shared actions, the mother fulfils the function of designation and imparting sense to the child's vital needs and bodily actions. The child's bodily actions in the dyad are initially inscribed in the psychological system of an "image of the world". The content and the structure of bodily actions are determined by the development of the system of significations and senses.

The earliest form of signification is evidently central to the analysis of psychosomatic development. It's realized in the language of sensuous (sensory and emotional) modality-as the initial step in the process of body image formation and as a mediating link between the earlier and the later developed forms of meaning. The next stage of developed corporeal psychosomatic phenomena has to do with the organizing role of the system of significations, which already exists at the level of representation and symbolic manipulation with regard to ideas. The main mediator of bodily actions is a verbalized body image, which acquires a multiplicity of semantic characteristics in the context of an integral "image of the world."

One can assume that transformation of semantic aspects of psychosomatic phenomena depends on the stages of development of the semantic, intentional component of child's activity (the succession of dominant activities, the emergence of new psychological structures). Thus, the basis for the existence of meaningful psychosomatic phenomena is communication with mother; a mother not only gives meaning to the corporeal phenomena for her child (verbally and in behavior) but also discloses, through her emotional reactions, the sense and the value of each phenomenon. The power of communicative meaning over bodily symptoms of a child is so great that a symptom may not only appear or take form in the process of communication but may also disappear completely. An example is the magic force of a mother's kiss, which "cures" any child's pain, and psychologically it is an essential substitute in the sense-of-body sensation: from suffering to love.

The stage of absolute predominance of the communicative meaning of corporeal phenomena coincides with the period of mother-child symbiotic attachment and is limited in time to the moment at which a child acquires autonomous, instrumental, self-directed bodily actions and manipulations with his own body. The communicative level of corporeality loses its relevance with age, and is relegated to the "psychological archives". However, it does not disappear, and in a situation of physical illness it may abruptly become relevant again and even serve as a source of a special class of psychosomatic symptoms- hysterical conversion (communication in the language of morbid physical state).

The next stage of development of psychosomatic phenomena is the inclusion in them of gnostic actions that acquire independent meaning and transform the mind-body connection. This stage is characterized by a child's interest in his own body and his search for the means of verbal or other forms of symbolic designation of bodily events. A child learns to distinguish and describe his own physical self, and a system of interceptive categories develops. The phenomenology of corporeality is no longer described by the formula "I am my body" but in another way, as "I have a body." In body image, semantic transformation shifts the functional value of certain body parts and the corporeal acts associated with them to center stage. It is also reflected in the way a child draws a human being: the typical "head and body" demonstrates, to use a term of 
E. Neizvestnyi, a "functional deformation" of the body image. It depends on the developmental stage of the semantic, intentional component of child activity (the succession of dominant activities, the emergence of new psychological structures). This stage is matched by a new class of body actions: imitative and assimilative. A child imitates an ill adult and unconsciously learns the family symptoms and the ways they are experienced and overcome emotionally, the stereotypes of response to pain and illness, etc. The significations, the meanings, and the body actions assimilated and appropriated in this period may have an influence on the process of symptom formation later, in adulthood: learned symptoms will be revived, and changes will occur in the semantic, normative characteristics of physical suffering (for example, in the form of a phobic response to body sensations in the region of heart, stomach, etc.).

This new stage in the socialization of corporeality involves the emergence of a reflective level of consciousness capable of transforming established semantic systems and generating new ones. The distinction between the body-self and the mind-self makes the body and its phenomena the participants in an inner dialogue that generates new, vitally important meanings. A paucity of reflexive psychological means can lead to chronicity of potentially pathogenic, alexithymic stereotypes of psychological regulation later on or to a primarily hysterical mode of symptom formation in psychosomatic disorders during life's difficult situations. It is probably here that we should also seek the origins of hypochondriacal personality traits.

Thus, it can be said that the mind-body phenomenon is an obligate consequence and a manifestation of the process of body functions socialization in individual development. A variety of corporeality phenomena reflects heterochronicity of genesis of different psychological systems and non-uniformity of psychological mediation. A "developed" psychosomatic phenomenon at the level of body's vital activity is an analogue of the higher mental functions: it is social in origin and in the nature of its functioning, has a complex system of psychological mediation and, in the course of development, becomes capable, in principle, of voluntary regulation.

Socialization of corporeality obviously has its own, evolving psychophysiology, which has still to be analyzed psychologically. It may be assumed that body systems do not remain quiescent in the course of their psychological mediation, but are transformed into new functional systems, which regulation necessarily includes a psychological element. The basic psychosomatic functional systems are probably formed quite early; and from that time on, corporeal and psychological events follow a path of co-evolution. The process of genesis and development of psychologically mediated functional systems takes place heterochronically, and the extent to which different bodily functions are psychosomatically implicated varies. The more expressions a body function finds in overt behavior, the more culturally embedded it is, and the more clearly its outward expression is regulated by a set of social norms. Sexual and respiratory functions and the reaction to pain head the list in this regard, and it is on the basis of these body functions that one can also observe a broad range of psychosomatic disorders.

Thus the concept of psychosomatic development marks out the key phenomena that represent development. It also describes the laws of development. We experience difficulties in marking out the key phenomena which form, determine the corporal development. The classification and the description of these phenomena exist, but the phenomenology of the normal development is not created yet. This situation is quite unique because there are a lot of descriptions of normal development in different fields of psychology (thinking, perception, emotions, and etc.), which help to explain some of abnormal phenomena. Just two normal corporal functions are included in psychology. They are the psychomotor acts (image psychology, regulation of activity by will) and the psychological phenomenon of appearance as one of the structural elements of self-image. But we can say that cultural and psychological reality forms more functional organ systems, corporal acts and phenomena. There should be a special task in the subject field of the clinical psychology of corporeality - the description and study of normal psychosomatic phenomena.

The possible search for normal developmental phenomena has to deal with the transfer of laws of psychological development into the psychosomatic ontogeny. From the point of the cultural-historical approach, the psychosomatic development has two dimensions: the external one, which is the process of socialization of corporal functions, and the inner one, which is the general "psycholization" of the body. The most important question is how the process of interiorization of the means of psychological body acts regulation takes place. According to our opinion, the joint emotion accompanying the key moments of corporal development plays the essential role during the early stages of psychosomatic ontogeny. 
Joint joy that accompanies all the stages of origin and fixing of psychosomatic connections provides normal development. In the case parental anxiety psychosomatic disorders may appear. The regulation of bodily activity as one of the main means of socialization can be expressed not only in punishment, but also in not expressing positive emotions. The result of socialization is the appearance of a "cultural body", which acquires its inner regulating system after taboo, imitation and special training. Thus we have to look for normal psychosomatic phenomena in joint emotions: joy, surprise, anxiety and others.

Another way to mark out phenomena of psychosomatic development is to analyze the structure of psychosomatic symptoms. One may try to determine phenomena of normal development by means of symptom appearance mechanisms. For example, in a disorder of normal development of communication and its symbols body language may lead to conversion. Child's simulative complains about stomach pains tell us that stomach is chosen among other body parts as an effective field of communication with mother. By means of this analysis the preliminary outline of psychosomatic phenomena can be determined (body image, pain image, categorical system of body representations, main body activity and acts, and etc.). The list of these subjects is open and should be filled up.

At present we can say that psychosomatic development follows age regularities and is determined by individual features, specific body experiences and social situation of development in general. Body perception, system of its representations depends upon age, level of verbal intellect, gender and experience of diseases. At first it is mostly guided by affective component. In the process of growth, the cognitive component that has information about corporal and pain experiences starts to play the main role. The categorical system becomes wider, emotional and somatic phenomena begin to separate from each other. Step by step the general category of personal body is formed. In case of deprivation there is a delay in the formation of body representations that can be noticed through disorders in categorical system, disease perceptions and misrepresented pain.

Child's internal picture of illness is very different from the adult's one and has its own structure. For little children the corporal state of health doesn't form the base of the inner image of disease. They pay attention mostly to their emotional feelings and adult's cognitive estimations. It also depends on how they endure the treatment. During adolescence the internal picture of illness starts its formation according to teen-ager's state of health; emotional perception of disease is determined by social and physical threat to his/her future. Cognitive estimation plays here the main role.

Structural and dynamic features of emotional experience can be described by level of differentiation and variety of experience, ways of copying with frustration. These features change and influence the psychological ontogeny. There is a pattern of emotional reactions that is common for children with psychosomatic disorders. It is formed by anxiety, prevalence of negative feelings, weak differentiation between positive and negative experience, which is influenced by inadequate understanding of mother's reactions and high dependence on mother.

The path by which psychosomatic symptoms emerge and acquire relevance is determined by the achieved level of corporeality socialization. Abnormal psychosomatic development has been studied very little up to now; but on the basis of explicit theoretical premises and phenomenological data, we can hypothesize several possible deviations in a child's psychosomatic development.

- Delay in socialization of body functions caused by a delay in the process of psychological mediation; the most graphic example is retardation in the development of habits of cleanliness, of voluntary regulation of movements, and of cultural forms of satisfying needs. The criterion here is deviation from a "standard" way, preestablished by social norms of carrying out corporeal actions.

- Regression of psychosomatic development; it may be shorttermed, as a reaction to difficulties in development (for example, a child with a poor sense of self may lose already socialized habits; he is unable to go to sleep or eat on his own, etc.). A more complex variant of regression involves activation of earlier semantic systems (as in a symptom of conversion) or transition to more primitive mechanisms of corporeality regulation (from reflexive thinking to affective reactions).

- Distortion of the course of psychosomatic development due to a distortion in the development of the overall system of psychological mediation: normative, semantic, and cognitive. Such distortion will affect the development of the physical self as a whole. This type of abnormal psychosomatic development is a product of disordered child-parent relations and system of upbringing.

Perhaps the above-described variants of abnormal psychosomatic development do not represent the full scope of its phenomenology, but 
they do enable us to construct a diagnosis of psychosomatic development under normal and pathological conditions on the unified, causaldevelopmental foundations.

The scope of corporeality phenomena unveiled in adult human being is the most difficult to understand. We find that they are "built into" the overall architectonics of the individual's mental life, into the semantic sphere of his personality; and during the course of development they form a special, highly significant, and emotionally charged unit. The more a physical phenomenon is enmeshed in a person's mental life, the more profound the "overall psychological accompaniment" is, i.e., the more complex and developed the system of mediation of physical manifestations in the strict sense is, and the more difficult it is to trace the contours of the psychosomatic phenomenon in an adult person.

Physical disorders give us a special area for analysis of body phenomena - the process of symptom and syndrome formation. At present we can suppose, that there are several basic paths of physical symptom development. We indicated earlier, that the psychological pathogenesis of a number of physical disorders involves deviations in the process of corporeality socialization in childhood, as well as distortions in the process of mediation of corporeal phenomena by signs and symbols and, more broadly, by psychological processes. This poses the task of studying how and under which conditions ontogenetically given stereotypes of psychosomatic response and regulation "become enmeshed" in the process by which psychosomatic disorders emerge and acquire relevance.

Another path of body symptoms shaping involves some psychological uniqueness of a situation of illness that forces a person to develop his own forms of psychosomatic engagement. Because illness is of major, vital significance, it focuses a person's mental engagement on itself and not only becomes an object of constant and preferential attention but also gives rise to a specific cognitive activity (nosognosia), which results in new psychosomatic formations - internal picture of illness, altered body image, and sense of self. Personality mechanisms mediating symptom formation and activity of self-regulation play a special role in emergence and psychological evolution of these formations These mechanisms determine the depth of a psychosomatic disorder (like symptom of symbolical conversion, the psycho-autonomic disorder, or an organic damage of some physical system); and the possibilities and the reserves of individual adaptation, control and successful compensation of the morbid condition to a considerable extent depend on them.

Psychosomatic disorders develop and acquire their relevance in a way similar to what occurs in this regard in childhood: the process is not confined to the level of intrapsychic mechanisms of mediation. In case of chronic physical ailment, a symptom necessarily becomes an element in the social situation surrounding the individual's development and existence. Firstly, a social situation can help revive a stereotypical psychosomatic response established in the process of individual development (for example, a propensity to get a headache or stomachache in response to a situation involving emotional difficulties). Secondly, the place of a symptom in the structure of situation and its relation to the person's integral semantic system determine such syndrome-forming characteristics as the value of a symptom, the limitation of its meaning and any contingent benefit it may have.

Thus, psychosomatic development continues in adulthood, drawing on accumulated psychosomatic experience and existing mechanisms of psychological mediation and regulation of corporeality, giving rise to a new class of complex psychosomatic phenomena and disorders: sense of self, internal picture of illness, hypochondria. The leading role played by the higher forms of activity the person, his self-awareness and reflection are the fundamental, distinguishing features of psychosomatic development in this period. One's activity in appearance of symptoms reflects not only the achieved level of development of mediative and self-regulatory mechanisms, but a certain path of one's psychosomatic development as well (Nikolaeva, Arina, 2003). According to the cultural-historical approach, the laws of normal and abnormal development are the same; therefore the analysis of self regulation and mediation processes could be used for psychosomatic phenomena description.

The psychology of corporeality as a science discipline and a new field in the Russian clinical psychology studies abnormal phenomena of the psychosomatic development in connection with the normal development, searches for instruments of analysis of corporal phenomena. The base if its methodology is assimilated with the Russian school of clinical psychology, headed by A.R. Luria and B.W. Zeigarnik. They insisted on studying abnormal phenomena in their connection with normal phenomena. One of their achievements is the theoretical and empirical claim for the necessity of the syndromic analysis. The category of psy- 
chological syndrome makes it possible to depict a structure of a disorder, to give a psychological interpretation of clinical phenomena, to describe psychological mechanisms of abnormal phenomena, and could be used in studies of psychosomatic phenomena. There should be a special type of syndrome which is called psychosomatic. The syndrome analysis is based on clearly formulated principles of the structural genetic analysis, therefore can not be used automatically in empirical research. Let's formulate some methodological preconditions for the use of syndromic analysis in the subject domain of psychology of corporeality.

It is necessary empirically and theoretically to allocate a psychological element, which will be the same in the course of normal psychological ontogeny of corporeality (the line of development) and in the process of symptom appearance (the line of a defect). Concrete forms of embodiment of symbolic regulation - semantic, cognitive, emotional mechanisms - determine the age dynamics in "psycholization" of corporeality, and are the central factors of symptom provoking in case of pathology. The object of research should be presented as a system with multiple causes both in normal development and structure of defect. The object of syndromic analysis should be described as possessing certain signs of plasticity: transformation and development of regulatory mechanisms.

From this point of view body is considered to be a hierarchically organized quasi-system with various levels of regulation and its damage (in different parts of nervous system and actually psychologically - at the level of sensations, body image and sense of body, its symptoms), including physiological, psychophysiological, intrapsychological and sociopsychological subsystems. This approach substantially answers the conventional biopsychosocial approach to psychosemantics. The organization of psychosomatic development is multilevel. At different stages of ontogeny the regulation of corporality phenomena changes from outer psychological to inner psychological according to the achieved level of mental development, in accordance with interiorization mechanisms. So, at early stages of corporeality socialization the outer psychological regulation is central, providing progress and laws of psychosomatic development, but in adults it exists basically in the curtailed form, though it can act as the leading psychological factor in appearing of symptoms (as in case of conversion disorder), subserving the processes of broken communications.

In psychology of corporeality it is supposed that plasticity of psychosomatic phenomena is connected with plasticity of brain functional systems (as in neuropsychology), as well as with age dynamics in psychological regulation of corporal phenomena. It is also linked to the demolition of these mechanisms during illness or semantic transformation of a person and changes in hierarchy of mediative mechanisms that may be directly emotional or reflective. Thus, the structure of a psychosomatic syndrome is a complex, hierarchically organized system of phenomena and mechanisms. It includes not only psychophysiological mechanisms at the level of inner psychological regulation, but likewise the factors of social situations of corporeality development, as the major determinants of symptom appearance.

The content and the borders of a psychosomatic syndrome are defined by a combination of symptoms of dysfunctions, both individually and nosospecified, as well as the phenomena of psychosomatic development and system of compensatory mechanisms and symptoms. From the psychological perspective, the essence of the syndrome is the interconnected and hierarchical system of the safe, developing and broken mechanisms of corporality and psychological self-control. The variable content of psychological factors in symptom appearance depends on the age and the reached level of corporeality mediation and means that a psychological syndrome is not identical to a clinical picture of corporal dysfunction.

The clinical dysfunction may correspond to several psychological syndromes. The conversion may serve here as an example of variable psychological content with a unified clinical definition. The same clinical constellation of symptoms in different psychological contexts gets a psychological polysemy, as it is formed with different cultural and symbolical mechanisms. For example, panting may reproduce the habitual stereotype of reaction learned in childhood, or may be the element of nonverbal communication of significant feelings, etc. Since the psychological sense of a symptom varies, so do the possibilities of psychotherapeutic influence, according to the age transformations and the leading mechanisms of symptom appearance.

The syndromic analysis completes two tasks in psychology of corporeality (as well as in neuropsychology and in pathopsychology). Firstly, it is the main methodological principle, and secondly, it is the means of empirical and diagnostic process. It provides a realization of the biopsychosocial model in the analysis of diseases and could also be used as the main means in diagnostics, as assistance in psychiatry and neurology. From this point of view a psychosomatic syndrome is a necessary step 
and one of the main instruments in establishing the diagnosis. This diagnostic process requires all the resources of clinical and psychological analysis. The syndromic analysis is an inalienable part of description of a complex disorder/defect structure. An applied result could be seen, for example, in the qualification of changes in higher psychological processes and psychological activity during chronic diseases at different ages, since various forms of diseases provoke certain morphological and multiple mental changes. These morphological and multiple mental changes lead to various defects of psychological processes including psychic dysontogenesis. A neuropsychological and pathopsychological qualification could be a part of a negative diagnosis, as it helps to differentiate psychosomatic disorder from other disorders including organic and psychotic. It is very difficult to define the so-called "specific gravity" of different factors in appearance of symptoms (organic, psychological, peripheral). A neuropsychological analysis shows which elements of central regulation are damaged and which factors play the main role. This analysis is suitable for almost every patient with complex etiology of suffering.

The stages and the tasks of an applied syndrome analysis are the following:

- the description of so-called "specific gravity" of psychological factors in all kinds of symptoms and states of health currently present in the clinical picture or found in the anamnesis. We could define the "specific gravity" by qualification of organic and psychological factors. After this procedure one can follow the next step, which is the reconstruction of a psychosomatic syndrome.

- the definition of the functional role of psychological experiences and mechanisms in appearance of all kinds of symptoms (isolated or interrelated). Four possible types of psychological factors in symptom appearance may be found. They are factors of disposition, factors of provocation, dynamic factors, and protective factors. Most of the known mechanisms of symptom appearance may be kept within the bounds of two functional roles. The understanding of these bounds is very useful and helpful in diagnostics and treatment. For example, the phenomenon of the "secondary advantage" leads mostly to a very prolonged disorder.

- the definition of topology of psychological factors as inner or outer factors. In different psychosomatic disorders a correlation between these factors could be different. In case of conversion the outer communication is the main factor.
- the description of psychological content in genesis of symptoms. This includes the analysis of structures of experience acquired during the psychological ontogeny.

- the qualification of mechanisms of symptom appearance in the context of individual development. It is possible if we analyze the whole life of a person: his/her family, culture, and epoch.

Thus the main content of psychological diagnostics in psychosomatic syndromic analysis must include analysis of mechanisms of symbolic mediation and its multiple-factor determination. The psychology of corporeality is methodologically ready to maintain the unique psychological instrument which is the syndromic analysis of psychological and psychosomatic phenomena. The model of psychotherapy should respond to these requirements, should consider special age traits, and should contain activity approach.

The clinical psychology of corporeality is characterized by a vast scope of bodily phenomena, mechanisms of regulation created through activity and development, adequate diagnostics, adequate psychotherapy. This allows inclusion of psychosomatic phenomena in the subject field of psychology, and further, in the field of other human sciences (philosophy, cultural anthropology, etc.).

There is a methodological unity between the clinical psychology of corporeality and the Russian general psychology.

- There is a shared notion about symbolically and culturally determined psychological phenomena.

- One of the main concepts in both disciplines is the concept of development (psychosomatic development).

- The phenomenological scope of the clinical psychology of corporeality includes abnormal as well as normal psychosomatic phenomena, their life-course development, psychological mechanisms of body development

- The active human role in development and transformation of bodily phenomena is emphasized and described.

Summing the abovementioned, there is a new independent understanding of the psychosomatic problem in the clinical psychology of corporeality, which differs considerably from those of the traditional medicine. In this light, the concepts of "psychosomatic symptom", "psychosomatic syndrome" and "psychosomatic unity" acquire new meanings. 


\section{References}

Alexander, F., French, T.M., and Pollock, G.H. (1968). Psychosomatic Specificity. Experimental Study and Results. Chicago: Univ. Chicago Press.

Antropov, U.F., and Shevchenko, U.S. (1999). Psikhosomaticheskie rasstrojstva $i$ patologicheskie privy'chny'e dejstviya u detej i podrostkov [Psychosomatic disorders and usual pathological acts of children and teenagers]. Moskva.

Arina, G.A., and Txostov, A.Sh. (1990). Teoreticheskie problemy issledovaniya vnutrennej kartiny bolezni [The theoretical problems of studying inner disease image]. In M.M. Kabanov (ed.). Psikhodiagnostika otnosheniya $k$ bolezni pri nervno-psikhicheskoj $i$ somaticheskoj patologii [Psychodiagnostics of attitude towards nerve-mental and somatic pathology]. Leningrad. P. 32-38.

Engel, G.L., and Schmale, A.H. (1967). Psychoanalytic theory of somatic disorder. J.Amer. Psychoanal. Ass., 15. P. 344-365.

Eudemiller, E.G., and Ustickiu, V.V. (1990). Family psychotherapy. Leningrad.

Isaev, D.N. (1996). Psikhosomaticheskaya medicina detskogo vozrasta [Psychosomatic medicine of childhood]. Sankt-Peterburg.

Lebedinsky, V.V. (1985). Narusheniya psikhicheskogo razvitiya u detej [Disorders of children's psychological development]. Moskva.

Motovilin, O.G. (2001). Razvitie predstavlenij o sobstvennom tele u detej v usloviyakh sem'i $i$ internata [Development of representations about own body among children living with families and without]. Author's abstract.

Nikolaeva, V.V., and Tishenko, P.D. (eds.). (1991; 1993). Telesnost' cheloveka: mezhdisciplinarny'e issledovaniya [Human corporeality: multiple studies]. Moskva.

Nikolaeva, V.V., and Arina, G.A. (1995). Tyazhelobol 'noj rebenok: shtrikhi k psikhologicheskomu portretu [A seriously ill child: sketch for psychological portrait]. School of health, 2. P. 10-21.

Polyakov, U.F. (1995). Teoretiko-metodologicheskie problemy' patopsikhlogii [Theoretical-methodological problems of pathopsychology]. In E.T. Sokolova, and V.V. Nikolaeva. Osobennosti lichnosti pri pogranichny'kh rasstrojstvakh [Special features of personality in case of the borderline personality and somatic diseases]. Moskva. P. 9-26.

Schur, M. (1955). Comments of the metapsychology of somatization. Psychoanal. Stud.Child., 10. P. 119-164.

Sifneos, P.E. (1973). The prevalence of "alexithymic" characteristics in psychosomatic patients. J.Psycother. Psychosom., 22. P. 255-262.

Sokolova, E.T. (1989). Samosoznanie i samoocenka pri anomaliyakh lichnosti [Selfawareness and self-appraisal in abnormal personality]. Moskva: MGU.

Tishenko, P.D. (1989). Zhizn' kak fenomen kul'tury' [Life as cultural phenomenon]. In A.P. Ogurczov, et al. (eds). Biologiya v poznanii cheloveka [Biology in getting to know a man]. Moskva: Nauka. P. 243-252.

Tkhostov, A.Sh. (2002). Psikhologiya telesnosti [Psychology of corporeality]. Moskva.

Vygotsky, L.S. (1982). [From the notebooks]. Vestnik Mosk. Univ. Ser. 14; Psihologiya, 1. P. 63-71. 